\title{
Remediation Through Transformation: Applying Educational Theory to the Struggling Resident
}

\author{
Benjamin Vipler, $M D^{1,2}{ }^{\oplus}$, Jennifer McCall-Hosenfeld, MD, MS $S^{1,2}$, and Paul Haidet, MD, \\ $\mathrm{MPH}^{1,2}$ \\ 'Division of General Internal Medicine, Penn State Milton S. Hershey Medical Center Hershey, PA, USA; ${ }^{2}$ Penn State College of Medicine Hershey, \\ PA, USA.
}

The struggling medical resident is faced with many adaptive challenges that may require change in mindset. However, formal remediation within graduate medical education (GME) often employs overly structured technical solutions to address trainee deficiencies. These strategies may ultimately fail to result in sustained improvement. Transformative learning (TL) is an educational theory that has recently been explored as a teaching modality in health professions education. In 2013, Cranton published a three-part framework for TL. This framework, composed of the cognitive perspective, beyond rational TL, and TL for social change, has potential applications to GME remediation, specifically in helping individuals to overcome adaptive challenges. These strategies may be particularly useful within the traditionally difficult-to-remediate competencies of systems-based practice, practice-based learning and improvement, and professionalism. The authors provide a descriptive overview of each of Cranton's perspectives, introducing concrete examples drawn from the medical literature. This article will contrast current remediation strategies with those using TL theory in order to assist graduate medical educators in applying these principles to the remediation of their own struggling residents.

KEY WORDS: transformative learning; remediation; adaptive challenge; graduate medical education; resident.

$\mathrm{J}$ Gen Intern Med 35(12):3656-63

DOI: $10.1007 / \mathrm{s} 11606-020-06036-1$

( ) Society of General Internal Medicine 2020

\section{INTRODUCTION}

The Accreditation Council for Graduate Medical Education (ACGME) tasks programs' Clinical Competency Committees to act as "early warning system[s] should a resident/fellow fail to progress." The literature suggests that up to $9 \%$ of residents develop significant personal, professional, or academic

Received December 10, 2019

Accepted July 3, 2020

Published online October 6, 2020 difficulties during their training. ${ }^{2,3}$ During the 2017-2018 academic year, over 1000 residents across all specialties were dismissed, withdrew (for reasons other than transferring), or did not successfully complete their training. ${ }^{4}$ Many resident difficulties require formal remediation, with one program citing an average prevalence of $28 \%$ of trainees requiring such interventions (with numbers as high as $42 \%$ during an individual year). ${ }^{5}$ Unfortunately, nearly a quarter of remediation efforts prove unsuccessful. ${ }^{6}$ Help avoidance and lack of insight on the part of trainees have been hypothesized to play a role. ${ }^{2,7}$ As a remediation resource, programs frequently utilize step-by-step guides organized by competency or behavioral milestone deficiency, each with corresponding recommendations. ${ }^{8,9}$ Plans may include everything from increased oversight and feedback to online modules. However, these methods do not always translate to successful remediation. One potential reason for this is that step-by-step guides are technical solutions for what may ultimately be adaptive challenges. Adaptive challenges are those that require change in one's mindset. ${ }^{10}$ The current technical nature common to many remediation plans may become a "box" for the trainee to check rather than a transformative experience aimed at growth.

\section{BACKGROUND}

In our experience, trainees who demonstrated the greatest remedial success appeared to emerge from remediation as new versions of themselves. These changes were often highlighted by unsolicited comments from faculty with whom the trainees worked before and after remediation. While successful remediation is often attributed to the degree of trainee motivation, this apparent individual transformation raises the question: To what degree can transformative learning (TL) theory inform this process?

Transformative learning (TL), as originally conceptualized by Jack Mezirow in the $1970 \mathrm{~s},{ }^{11}$ differs from pure knowledge attainment in that it "shapes people; they are different afterward, in ways both they and others can recognize."12 Cranton later framed TL into 
three perspectives: cognitive (whereby experience leads to development through critical reflection), ${ }^{13}$ beyond rational (perspective transformation through unconscious, emotional, or other means besides critical reflection), and social change (transformation with the goal or outcome of challenging oppression). ${ }^{14,15}$ It should be noted that while these TL lenses traditionally describe learning, we are interested in applying these theories to educating and teaching. The act of fostering TL is already well established in the adult education literature, ${ }^{16}$ and we hope to explore how these perspectives may serve as distinct pedagogies in medical education (in particular, remediation). While the current literature on TL in remedial medical education focuses primarily on Cranton's cognitive perspective, ${ }^{17}$
Cranton's other two perspectives have additional implications for the struggling medical learner and thus warrant exploration. In the sections that follow, we will explore Cranton's framework in depth and use models drawn from the literature to assist graduate medical educators in constructing enhanced remediation strategies that are more comprehensive, grounded in sound educational theory, and may be more likely to produce their intended outcomes.

\section{COGNITIVE PERSPECTIVE}

\begin{abstract}
Dr. M is a new intern who recently graduated at the top of his medical school class. Despite a good fund of knowledge, he has struggled with being able to manage the increased amount of patient data that comes with his new role on the inpatient team. Additionally, he is not yet facile with his new electronic health record. When given feedback on his performance by his senior resident and attending physician, Dr. M is resistant, citing his prior success in medical school.
\end{abstract}

The cognitive perspective of transformative learning begins with the first step of experiencing a "disorienting dilemma." 11,15 This emotionally charged life event challenges the learner's worldview (also called a frame of reference, meaning scheme, habit of mind, or point of view), causing him or her to self-assess underlying assumptions and recognize discomfort. Next, the learner explores new roles, before a new course of action is set. Knowledge and skills are then acquired to function in these new roles, before they are attempted, developed, and reintegrated into the individual's life. Some argue that the disorienting dilemma can be created by the teacher. ${ }^{18,19}$ Frequent experiences outside the learner's comfort zone may create the level of disorientation needed to stimulate largescale change. Medical education has abundant examples of such disorienting dilemmas. ${ }^{19-21}$

Educator empowerment is key to the adoption of TL in GME remediation. After the competency committee diagnoses learner deficiencies, an individual faculty mentor (hereon referred to as a "remediation coach") is often assigned to help the struggling learner. Both the competency committee and remediation coach have unique roles in identifying the disorienting dilemma and facilitating critical reflection through rational discourse. This process of a resident-coach pair collaboratively identifying disorienting dilemmas has already been reported in the literature. ${ }^{21}$ However, there are additional implications pertaining to coaching in the context of remediation. For many high-achieving medical trainees, failing a rotation or being recommended for remediation may, in itself, be a disorienting dilemma to be harnessed. Alternatively, educators may create experiences that function as disorienting dilemmas. If a trainee is deficient in recognizing system error and advocating for improvement, the educator could facilitate an interview of a patient who was harmed by a preventable medical error. If a trainee fails to practice cost-effective care, an immersion in the hospital billing department or with a collections agency may prove useful. If a 
trainee has been identified as inconsistently demonstrating respect for members of the interprofessional team, anonymous $360^{\circ}$ evaluations may provide insight for reflection. Utilizing TL may be of greatest value when remediating a trainee who struggles with learning and improving via feedback ${ }^{22}$; as such, simply providing additional feedback and hoping for improvement would be futile. However, such change may still be resisted, ${ }^{23}$ particularly when the disorienting dilemma evokes emotions such as bitterness, anger, or fear. ${ }^{13}$

\section{Upon finding out that he was reviewed by the competency committee, Dr. Mis distraught \\ [disorienting dilemma]. He has never before performed below average, and is questioning his worthiness for internship. Noting Dr. M's distress, his chief residents encourage him to reflect on his underlying assumptions regarding feedback he received [rational discourse]. Through this reflection, Dr. Mrecognizes that he holds the belief of himself as a self-directed learner and that if he accepts feedback from supervisors, his values are questioned [current meaning scheme]. However, Dr. M's emotional response to his remediation triggers him to attempt a new path forward. He realizes that in order to improve he needs to appreciate the views of his supervisors. Dr. M is paired up with a high-functioning upper-level resident to learn pre- rounding skills. He begins using a notebook to identify rotation goals and document feedback [practice-based learning and improvement]. He takes it upon himself to search for online videos of tips and tricks for his specific health record, now recognizing that self-regulation and feedback acceptance are not mutually exclusive [new meaning scheme].}

Tips for educators to foster transformative learning in remediation:

- Help trainees " $[$... $]$ move from an argumentative mindset to an empathic understanding of others views [...]"13,24

- Mentors should recognize trainees' emotional responses to disorienting dilemmas and use them to guide reflection. ${ }^{25,26}$ Moreover, educators may create scenarios to provoke desired emotional responses from learners in order to foster reflection on themselves or their profession. ${ }^{27}$

- When giving feedback, be objective, keep all statements open to question, and promote mutual understanding by weighing the evidence and strength of supporting arguments. ${ }^{28}$

\section{BEYOND RATIONAL PERSPECTIVE}




Dr. C was cited during her intern year for "professionalism issues, " including being
unprepared on patient presentations, late submitting clinical documentation, and not showing
up to multi-disciplinary rounds. During a stern meeting with her program director, all of the
consequences of continued lapses in professionalism were laid out. Dr. C is now a second-
year resident who again finds herself under review by the competency committee due to lack of
sustained improvement. The program leadership is baffled by Dr. C's performance given her
heartfelt plea that she is trying to improve.

While the cognitive perspective denotes a very rational, thoughtful method of transformation, Cranton's second perspective, "beyond rational" transformative learning, focuses more on unconscious change. ${ }^{15}$ Some of these unconscious factors include behaviors in support of or contrary to a given goal, hidden motives and competing commitments limiting achievement, and assumptions underlying these motives. The immunity-to-change model of coaching ${ }^{29}$ has been touted as a "transformative learning process" 10 and is grounded in exploring these unconscious factors that limit individual or organizational change. We believe this process of TL to most closely resemble Cranton's beyond rational perspective. In the medical literature, immunity-to-change has been applied to patient education, and may have relevance for GME, particularly in areas such as remediation, where a change in behavior is desired. For example, unintentional medication nonadherence has been identified as an adaptive challenge (as described earlier, a challenge overcoming which requires a complete change in one's mindset, rather than via an algorithmic or linear approach). ${ }^{10}$ Similar to the motivated but struggling medical learner, the non-adherent patient often demonstrates desire to continue his or her medications. Moreover, articulating a rational reason for adherence issues (or in the learner's case, academic struggles) may prove challenging. Interviews to uncover hidden motives for non-adherence and the creation of chart-like "immunity maps" have been used to bring attention to possible underlying cause(s) for nonadherence. $^{10}$ These maps are designed to foster insight, and contain four free-text columns where the individual documents his or her improvement goal, what they are doing or not doing instead of the identified goal, any competing commitments or worries limiting goal achievement, and any assumptions leading to those worries. This model has also been utilized in the curriculum development literature, and "[...] has potential for broad applicability as medical educators seek to change what has previously been consider unchangeable."30 We believe GME remediation to be one of these potential applications.

Exploration of the beyond rational perspective highlights the limitations of applying technical solutions to adaptive problems. $^{14,15}$ In GME remediation, these technical solutions are often in the form of "more of the same [...] knowledge or skills teaching" that were unsuccessful the first time around. ${ }^{31}$ The immunity-to-change model is a strategy that attempts to look beyond behavior to what drives behavior, focusing on intervening there. Application of immunity-to-change to GME remediation could demonstrate the underlying nature of a trainee's struggles, bringing conscious awareness to unconscious behaviors that are limiting success, and addressing the underlying assumptions perpetuating these behaviors. The creation of immunity maps highlights the internal process of discovering insights and epiphanies. ${ }^{15,32}$ The remediation coach may be extremely helpful in drawing attention to emotions in a learning experience. Fostering this TL perspective may be more beneficial for remediating trainees who do not have a significant emotional response to academic difficulties. 


\begin{abstract}
Dr. C's remediation coach asks her to identify exactly what she is doing that causes her to be unprepared, late, or absent [hidden competing commitment]. She recognizes that she is often at her patients' bedsides when needed elsewhere [behaviors that go against the goal]. She acknowledges her belief that being physically present with her patients was of ultimate importance [big assumption]. She now realizes her absences from other responsibilities may be offsetting her good bedside manner and negatively affecting overall patient care. She works toward a more balanced schedule, ensuring adequate time at the bedside without sacrificing her education [improvement goal].
\end{abstract}

Tips for educators to foster transformative learning in remediation:

- Help trainees make meaning of their experiences. ${ }^{13,33}$ Immunity-to-change may be used as a guide.

- Through "compassionate criticisms," educators can assist trainees in questioning their present assumptions and to create a path forward. ${ }^{13,34}$
- Uncover blind spots in the value systems of trainees, helping them practice through a new lens. ${ }^{35}$

$$
\begin{aligned}
& \text { Dr. J is a third year resident who has been identified as ready for unsupervised practice } \\
& \text { across nearly all competencies. However, Dr. J's inpatient attending notices that a significant } \\
& \text { amount of patients she discharged were readmitted. When asked why this might be, Dr. J } \\
& \text { reviews her prior discharge summaries and highlights her clear instructions regarding } \\
& \text { medication administration, dietary changes, and follow-up appointments. }
\end{aligned}
$$

Cranton's third perspective is transformative learning for social change. This perspective focuses on "challeng[ing] and transform[ing] oppressive structures in society," (sometimes referred to as conscientization). ${ }^{15}$ Public, global, and population health are of increasing importance in an ever-connected world. Additionally, medical schools are rapidly adopting health systems science curricula. ${ }^{36,37}$ The connection between this third perspective and medical education can become more lucent through the striking parallels between TL for social change and the process improvement models integral to GME. ${ }^{15,38-40}$ The TL literature describes finding learners and facilitators who discuss concerns of daily life and taking action against oppressive structures. This closely mirrors the healthcare process improvement steps of forming a team, setting aims, and selecting, testing, implementing, and spreading changes. ${ }^{38}$

There are multiple examples of transformative learning for social change through care of the medically underserved. ${ }^{25,41-}$ ${ }^{43}$ While these experiences highlighted active learning, an interactive approach to TL for social change may result in a higher engagement. ${ }^{44}$ This was demonstrated in a singlecenter study where self-regulated learning through medical student team-created videos exploring the societal role of the physician and the importance of social determinants of health 
were shown to be interesting, enjoyable, and preferred over all prior methods used to teach on these topics, including simple field visits. ${ }^{45,46}$

Another potential application of TL for social change in GME remediation is when a trainee struggles with "recogniz[ing] system error and advocate[ing] for system improvement." ${ }^{22}$ Here, the goal is to help the trainee move from "passive acceptance of their situation, to realizing they can have some influence," 15 to "becom[ing] an active agent in constructing a different, more just reality." ${ }^{15,47}$ While a disorienting dilemma harnessed for personal practice improvement falls under the cognitive perspective of TL and the competency of practice-based learning and improvement, if that same disorienting dilemma is harnessed for system-level improvements, this can shift the perspective of TL toward social change and the competency of systems-based practice. ${ }^{48}$ While outside the scope of our manuscript, it should be noted that health systems science education through this lens is not limited to use only in the struggling learner.

Dr. J and her attending speak directly with the readmitted patients, specifically querying

medication adherence, dietary indiscretions, and attendance at follow-up appointments. Many

of the patients couldn't afford prescriptions, healthier food, co-pays, or appointment

transportation. Dr. J's remediation coach suggests she pair with a colleague to complete a

post-discharge home visit for a patient [empowerment]. Dr. J is alarmed by the poverty she

sees and immediately recognizes the health impact [disorienting dilemma]. With patient

consent, she performs in-home video interviews of her patients and shows her co-residents,

who are equally alarmed. Dr. J and her co-residents work with their inpatient pharmacist to

create medical record alerts when cheaper medication alternatives are available [systems-

based practice].

Tips for educators to foster transformative learning in remediation:

- Empower trainees to learn about and advocate for the health of their patients. ${ }^{13}$

- Encourage trainees to move from theoretical and conceptual work into practice ${ }^{13}$ (e.g., help them formalize process improvement ideas into health systemimproving projects).

- Provide opportunities and funding support for trainees to work in resource-limited settings. ${ }^{25}$

\section{CONCLUSION}

Adoption of TL in the medical education world has been slow. The first published literature review of TL in health professions education excluded GME. ${ }^{49}$ This presents numerous opportunities for future study. First, a formal literature review of TL in GME would provide an important state of the science with respect to this methodology. Second, "Providing detailed and practical guidelines for educators in the health professions about facilitating TL [...]" ${ }^{\prime 49}$ should be included in faculty development. Third, since there are no studies comparing initiatives that foster TL with other educational methods, ${ }^{13}$ meaningful evaluation of outcomes when remediating with TL is needed. These may include graduation rate, patient satisfaction scores, or ideally, clinical outcomes. However, the literature argues that assessment of TL should be performed qualitatively ${ }^{19}$ or through mixed-methods. ${ }^{50,51}$ Thus, remediation success using a transformative approach should include at least some qualitative evaluator data, rather than heavy reliance on numeric milestone-based rotation evaluation scores. Lastly, in educational settings where TL is structured, attention should be paid not only to individuals who have transformative experiences but also to those who do not report transformation. This may provide important insights into faculty development on motivating learners. 
Current best practices for remediating struggling medical learners involve technical, step-by-step methods, often addressing one deficit at a time. ${ }^{7,9,27}$ While we are not advocating for a complete jettison of these well-established remediation strategies, we believe these are technical frameworks that, in isolation, may not work for the adaptive challenges facing the struggling resident. The strong emotions inherent to TL experiences may have great potential for motivation ${ }^{13}$ and may be used in tandem with some current remediation strategies to optimize success. Ultimately, through its three foundational perspectives, transformative learning presents a promising framework to guide medical educators in creating the adaptive solutions that are needed in remediating our struggling residents.

Corresponding Author: Benjamin Vipler, MD; Division of General Internal Medicine, Penn State Milton S. Hershey Medical Center Hershey, PA, USA (e-mail: bvipler@pennstatehealth.psu.edu).

\section{Compliance with Ethical Standards:}

Conflict of Interest: The authors declare that they do not have a conflict of interest.

\section{REFERENCES}

1. Andolsek K, Padmore J, Hauer K, Edgar L, Holmboe E. Clinical Competency Committees: A Guidebook for Programs. https://www. acgme.org/Portals/0/ACGMEClinicalCompetencyCommitteeGuidebook. pdf. Published 2017. Accessed 6 Aug 2019.

2. Yao DC, Wright SM. National survey of internal medicine residency program directors regarding problem residents. JAMA 2000;284(9): 10991104

3. Reamy BV, Harman JH. Residents in trouble: an in-depth assessment of the 25-year experience of a single family medicine residency. Fam Med 2006;38(4):252-257.

4. ACGME. Data Resource Book Academic Year 2018-2019. In: Analysis DoAaD, ed. Chicago, IL: Accreditation Council for Graduate Medical Education; 2019.

5. Schwind CJ, Williams RG, Boehler ML, Dunnington GL. Do individual attendings' post-rotation performance ratings detect residents' clinical performance deficiencies? Acad Med 2004;79(5):453-457.

6. Bhatti NI, Ahmed A, Stewart MG, Miller RH, Choi SS. Remediation of problematic residents-A national survey. Laryngoscope 2016;126(4):834838.

7. Guerrasio J. Remediation of the struggling medical learner. 2nd edition. ed. Irwin: Association for Hospital Medical Education; 2018.

8. Yakes E, Ann., Brady DW, McPherson JA, Ryder HF, Friedman HP Consistency Is Key: Tools and Strategies for Developing a "LitigationLight” Competency-Based Remediation Plan for Your Residents. In. APDIM Spring Meeting 2017.

9. Guerrasio J, Garrity MJ, Aagaard EM. Learner deficits and academic outcomes of medical students, residents, fellows, and attending physicians referred to a remediation program, 2006-2012. Acad Med 2014;89(2):352-358.

10. Krousel-Wood M, Kegan R, Whelton PK, Lahey LL. Immunity-tochange: are hidden motives underlying patient nonadherence to chronic disease medications? Am J Med Sci 2014;348(2):121-128.

11. Mezirow J, Marsick V. Education for Perspective Transformation. Women's Re-entry Programs in Community Colleges. 1978.

12. Clark MC. Transformational learning. New Directions for Adult and Continuing Education. 1993;1993(57):47-56.

13. Merriam SB, Baumgartner L, Jossey-Bass Inc. Learning in adulthood : a comprehensive guide. Fourth Edition. ed. San Francisco: Jossey-Bass; 2020.

14. Cranton P. Transformative learning. In: Mayo P, ed. Learning with Adults: A Reader. Rotterdam.: Sense Publishers.; 2013:267-274.
15. Merriam SB, Bierema LL. Adult learning : linking theory and practice. First edition. ed. San Francisco: Jossey-Bass, a Wiley brand; 2014.

16. Taylor EW. Fostering Transformative Learning. 1st ed. San Francisco: Jossey-Bass; 2009

17. O'Callaghan P, McCarthy KE, DeWaay DJ. Chapter 9: Using Transformational Learning as a Framework for Medical Student Remediation Experiences and Professional Identity Formation. In: Boden CJ, Peno K, Carter TJ, eds. Adult learning in professional, organizational, and community settings. Charlotte: Information Age Publishing Inc.,; 2019.

18. Brookfield S. Powerful techniques for teaching adults. In: The JosseyBass higher and adult education series. San Francisco: Jossey-Bass, a Wiley Imprint,; 2013.

19. O'Connell CB. Enhancing transformative learning in physician assistant education. J Physician Assist Educ 2010;21(1):18-22.

20. Thompson BM, Teal CR, Rogers JC, Paterniti DA, Haidet P. Ideals, activities, dissonance, and processing: a conceptual model to guide educators' efforts to stimulate student reflection. Acad Med 2010;85(5):902-908

21. Gonzalo JD, Wolpaw DR, Krok KL, Pfeiffer MP, McCall-Hosenfeld JS. A Developmental Approach to Internal Medicine Residency Education: Lessons Learned from the Design and Implementation of a Novel Longitudinal Coaching Program. Med Educ Online 2019;24(1):1591256.

22. Iobst wC. https://www.acgme.org/Portals/0/PDFs/Milestones/ InternalMedicineMilestones.pdf. Published 2015. Accessed 6 Aug 2019.

23. Thomas PA, Kern DE, Hughes MT, Chen BY. Curriculum development for medical education : a six-step approach. Third edition. ed. Baltimore: Johns Hopkins University Press; 2016.

24. Mezirow J. Learning to think like an adult. 1st ed. San Francisco: Jossey-Bass; 2012

25. Sawatsky AP, Nordhues HC, Merry SP, Bashir MU, Hafferty FW. Transformative Learning and Professional Identity Formation During International Health Electives: A Qualitative Study Using Grounded Theory. Acad Med 2018;93(9):1381-1390.

26. Lange EA. Transformative and Restorative Learning: A Vital Dialectic for Sustainable Societies:. Adult Educ Q. 2004;54(2):121-139.

27. Cason D, National Association of EMS Educators. Foundations of education : an EMS approach. Mosby Jems, Elsevier,. Table of contents http://www.loc.gov/catdir/toc/fy0605/2005044395.html. Published 2006. Accessed.

28. Taylor Ew. The Theory and Practice of Transformative Learning: A Critical Review. Information Series No. 374. 1998.

29. Kegan R, Lahey LL. Immunity to change : how to overcome it and unlock potential in yourself and your organization. Boston.: Harvard Business Press; 2009.

30. Gonzalo JD, Haidet P, Blatt B, Wolpaw DR. Exploring challenges in implementing a health systems science curriculum: a qualitative analysis of student perceptions. Med Educ 2016;50(5):523-531.

31. Cleland J, Leggett H, Sandars J, Costa MJ, Patel R, Moffat M. The remediation challenge: theoretical and methodological insights from a systematic review. Med Educ 2013;47(3):242-251.

32. Dirkx JM. Nurturing soul work: A Jungian approach to transformative learning. The handbook of transformative learning: Theory, research, and practice. 2012:116-130.

33. Daloz LA. Mentor : guiding the journey of adult learners. Second edition with new foreword, preface, and afterword. ed. San Francisco: JosseyBass, a Wiley imprint; 2012.

34. Boyd RD, Myers JG. Transformative education. Int $\mathrm{J}$ Lifelong Educ 1988;7(4):261-284

35. Lewin LO, McManamon A, Stein MTO, Chen DT. Minding the Form That Transforms: Using Kegan's Model of Adult Development to Understand Personal and Professional Identity Formation in Medicine. Acad Med 2019;94(9): 1299-1304.

36. Skochelak SE, Hawkins RE, AMA Education Consortium. Health systems science. First edition. ed. Philadelphia: Elsevier; 2016.

37. Gonzalo JD, Ogrinc G. Health Systems Science: The "Broccoli" of Undergraduate Medical Education. Acad Med 2019;94(10):1425-1432.

38. Institute for Healthcare Improvement: How to Improve. 2019.

39. Langley GJ. The improvement guide : a practical approach to enhancing organizational performance. 2nd ed. San Francisco: Jossey-Bass; 2009.

40. ACGME Common Program Requirements (Residency). https://www. acgme.org / Portals / O / PFAssets / ProgramRequirements / CPRResidency2019.pdf. Published 2019. Accessed 6 Aug 2019.

41. Hofmeister $\mathbf{S}$, Soprych A. Teaching resident physicians the power of implicit bias and how it impacts patient care utilizing patients who have experienced incarceration as a model. Int J Psychiatry Med 2017;52(46):345-354. 
42. Van Wieren A, Palazuelos L, Elliott PF, Arrieta J, Flores H, Palazuelos D. Service, training, mentorship: first report of an innovative educationsupport program to revitalize primary care social service in Chiapas, Mexico. Glob Health Action 2014;7:25139.

43. Van Schalkwyk SC, Bezuidenhout J, De Villiers MR. Understanding rural clinical learning spaces: Being and becoming a doctor. Med Teach 2015;37(6):589-594.

44. Chi MTH, Wylie R. The ICAP Framework: Linking Cognitive Engagement to Active Learning Outcomes. https://doi.org/10.1080/ 004615202014965823. 2014.

45. Woratanarat T. Ethnographic edutainment for transformative medical education: Thailand. Int $\mathrm{Q}$ Community Health Educ 2014;35(1):85-93

46. Woratanarat T. Higher satisfaction with ethnographic edutainment using YouTube among medical students in Thailand. J Educ Eval Health Prof 2014;11:13.

47. Merriam SB, Caffarella RS, Baumgartner L. Learning in adulthood : a comprehensive guide. 3rd ed. San Francisco: Jossey-Bass; 2007.
48. Wittich CM, Reed DA, McDonald FS, Varkey P, Beckman TJ. Perspective: Transformative learning: a framework using critical reflection to link the improvement competencies in graduate medical education. Acad Med 2010;85(11):1790-1793.

49. Van Schalkwyk SC, Hafler J, Brewer TF, et al. Transformative learning as pedagogy for the health professions: a scoping review. Med Educ 2019;53(6):547-558.

50. Stuckey HL, Taylor EW, Cranton P. Developing a Survey of Transformative Learning Outcomes and Processes Based on Theoretical Principles:. https://doi.org/10.1177/1541344614540335. 2014

51. Stuckey HL, Taylor EW. Transformative Learning Survey. Woodward Endowment For Medical Science Education. http:// transformativelearningsurvey.com/. Published 2019. Accessed.

Publisher's Note: Springer Nature remains neutral with regard to jurisdictional claims in published maps and institutional affiliations. 